Article

\title{
Sport and Sustainable Development Goals in Spain
}

\author{
Javier Campillo-Sánchez ${ }^{1}$, Eduardo Segarra-Vicens ${ }^{2}{ }^{2}$ Vicente Morales-Baños ${ }^{2, *}$ and Arturo Díaz-Suárez ${ }^{2} \mathbb{D}$ \\ 1 Sports Councillor of the Santomera Town Council, 30140 Santomera, Spain; javicampillo86@gmail.com \\ 2 Faculty of Sports Sciences, University of Murcia, Campus Mare Nostrum, 30720 Santiago de la Ribera, Spain; \\ esegarra@um.es (E.S.-V.); ardiaz@um.es (A.D.-S.) \\ * Correspondence: vela@um.es
}

Citation: Campillo-Sánchez, J.;

Segarra-Vicens, E.; Morales-Baños, V.; Díaz-Suárez, A. Sport and Sustainable Development Goals in Spain.

Sustainability 2021, 13, 3505.

https://doi.org/10.3390/su13063505

Academic Editor: Franklin G. Mixon

Received: 8 February 2021

Accepted: 19 March 2021

Published: 22 March 2021

Publisher's Note: MDPI stays neutral with regard to jurisdictional claims in published maps and institutional affiliations.

Copyright: () 2021 by the authors. Licensee MDPI, Basel, Switzerland. This article is an open access article distributed under the terms and conditions of the Creative Commons Attribution (CC BY) license (https:// creativecommons.org/licenses/by/ $4.0 /)$.

\begin{abstract}
Sport is a valuable tool for sustainable development. This is recognized in the Kazan Action Plan, in the 2030 Agenda, itself, and in the Action Plan for its implementation in Spain. In order to broaden the scope of the Sustainable Development Goals (SDGs), it is necessary to carefully consider both the possible synergies and existing inconsistencies that can enhance and weaken the contribution of sport to sustainable development. Taking as reference the international recommendations in this regard, it will be necessary to take into account the concept of "policy coherence" in both its vertical and horizontal dimensions. Advancing in the achievement of the SDGs largely requires involving subnational governments and the rest of the stakeholders, promoting decision-making based on concrete and reliable common indicators. Starting from the methodology developed globally by the Sustainable Development Solutions Network (SDSN) for locating the SDGs, a comparative analysis of the sports situation of each Spanish Autonomous Community will be carried out as a diagnosis. This is to show the existing inequalities between territories in relation to the selected indicators and, at the same time, identify some of the main limitations and gaps that we currently find in Spain to perform this location in a more effective way.
\end{abstract}

Keywords: sport; physical activity; Sustainable Development Goals; Agenda 2030; policy coherence; policy lever

\section{Introduction}

The Sustainable Development Goals (SDGs) and the 2030 Agenda are an agreed plan of action to achieve global development challenges by 2030. At the United Nations Sustainable Development Summit in September 2015, member states agreed that the Millennium Development Goals (MDGs) would be succeeded by the new SDGs. World leaders from 193 countries approved a document with 17 Sustainable Development Goals and 169 targets, in order to end extreme poverty over the next 15 years, reduce inequalities and injustice and reverse climate change. This document is universally known as the 2030 Agenda and includes these three fundamental dimensions: economic prosperity, social equality and environmental sustainability in a universal way for all countries [1].

This ambitious project requires a global perspective, multilevel policies and alliances that allow the mobilization of resources in an effective and efficient way. The approach must be participatory and of shared responsibility. The appropriation of the Agenda by regional and local governments will be of vital importance, adapting the global goals to their realities and contexts through the elaboration of their own strategies. These strategies should make known the content and principles of the Agenda, its universal character, its relevance and its impact. For this, it will be necessary for these strategies or action plans to include in their methodologies monitoring and evaluation systems as well as accountability [2].

The management of physical activity and sport is an excellent opportunity as a multidisciplinary development factor. This is stated in the 2030 Agenda, itself, which recognizes sport as a unique tool to support this World Plan of Action, considering it "an 
important enabler of sustainable development. We recognize the growing contribution of sport to the realization of development and peace in its promotion of tolerance and respect and the contributions it makes to the empowerment of women and of young people, individuals and communities as well as to health, education and social inclusion objectives" [1].

Numerous authors have highlighted its importance along the same lines: "Sport is constantly gaining space in public consideration and political attention. It is incorporated into the habits, customs and lifestyles of the people, progressively and steeply. Over time, it has become not only an extraordinary instrument for disease prevention and health promotion but also a powerful educational tool and platform for social inclusion and integration" [3].

Instead, as suggested by leading articles on the subject, such as the one by Lindsey and Darby, it is convenient to look for "political coherence" as a valuable concept to consider in order to identify factors that can allow and limit the different potential contributions of sport to the different SDGs. Based on the definition offered by Ashoff, the term "political coherence" is used in two senses: on the negative side, it means the elimination of inconsistencies, that is, of inconsistencies between and the mutual deterioration of different policies. On the positive side, it means the interaction of policies with a view to achieving overriding objectives. In keeping with the dualism of this statement, the terminology of inconsistencies and synergies, respectively, to reflect contradictory or complementary aspects of different policies, is common within the policy coherence literature [4].

Policy coherence is also presented as a multilevel concept [4]:

"Vertically," meaning it is applicable in global, international, national and subnational policies and in the whole range of countries that may be involved or affected by development agendas.

"Horizontally," which refers to the expansion in the implementation of policies to encompass civil society, private organizations and public sector institutions.

This search for coherence of policies at both levels in sports subjects led UNESCO, in 2017 to develop the Kazan Action Plan [5], which is a commitment by the international community to link the development of sport policy to the United Nations 2030 Agenda. This Action Plan proposes, as one of its main areas of action, "to maximize the contribution of sport to sustainable development and peace," putting in place measures that reinforce the harmonization between sport policies and the SDGs. Taking as a reference these measures and the proposal of the Commonwealth Secretariat [6], we can highlight the following SDGs and global targets of the 2030 Agenda to which sport contributes more directly:

SDG 3, Health and Wellbeing (target 3.4): Improve the health and wellbeing of all at any age.

SDG 4, Quality Education (target 4.7): Provide quality education and promote lifelong learning for all and the acquisition of skills through sport.

SDG 5, Gender Equality (targets 5.1 and 5.5): Promote equality between men and empower women and girls.

SDG 8, Decent Work and Economic Growth (targets 8.1 and 8.6): Facilitate economic growth and full and productive employment and work for all.

SDG 10, Reduction of Inequalities (target 10.2): Build peaceful, inclusive and equitable societies.

SDG 11, Sustainable Cities and Communities (target 11.7): Make cities and settlements inclusive, safe, resilient and sustainable.

SDG 12, Responsible consumption and production (targets 12.6 and 12.8): Guarantee sustainable consumption and production patterns.

SDG 13, Climate Action (Target 13.1): Take urgent measures to combat climate change and its effects.

SDG 16, Peace, Justice and Strong Institutions (Target 16.6): Build effective and inclusive accountable institutions at all levels.

The SDGs, unlike the MDGs, are conceived as universal, integrated and indivisible. Therefore, in addition to these nine Sustainable Development Goals to which sport con- 
tributes in a more direct and efficient way, it is important to include SDG 17 (Partnerships to achieve the Goals), since it includes specific goals related to the strengthening of this World Alliance for Sustainable Development. Specifically, Target 17.14 of the SDGs seeks, as has been mentioned, to "improve policy coherence for sustainable development" [1]. Sports policies and strategies must also be aligned with this global plan for sport to act effectively as a multiplier lever in its contribution to the SDGs. Therefore, SDG 17 represents the 10th SDG, to which physical activity and sport are related in this international framework of reference.

Along the same lines, in Spain, the Action Plan for the Implementation of the 2030 Agenda [7] states that "sport is occupying a transversal space in contemporary societies. It affects health, education, culture, gender issues and integration issues. Sustainable development must take this reality into account and take advantage of it."

We will refer to sport as the generic term that refers to "any form of physical activity that, through organized participation or not, is aimed at expressing or improving physical and mental condition, the development of social relationships or the obtaining results in competition at all levels" [8].

The essential nature of sport in our society has remained even more latent, if possible, in the current context of pandemic. In a manifesto prepared by the COLEF Council [9], the reasons why physical exercise should be promoted are compiled, to be highlighted:

The practice of physical education, physical activity and sport is a fundamental right included in the Spanish Constitution, the White Book of Sport of the European Commission [8] and UNESCO [10].

Sedentary lifestyle is a serious public health problem:

Physical inactivity is one of the main causes of at least 35 chronic diseases [11].

Physical exercise improves the prognosis of 26 chronic diseases [12].

"The mean global burden of premature mortality averted by physical activity is $15.0 \%$, which is conservatively equivalent to 3.9 million deaths annually" [13].

"Physical inactivity is responsible for $13.4 \%$ of deaths per year in Spain, leading to more than 52,000 lives. This represents a significant economic burden for the country of more than 1560 million euros, which is paid for by $70.5 \%$ by public administrations (while $22.8 \%$ is disbursed by Spanish households)" [14].

In addition, in the aforementioned manifesto, they warn of an aggravation of the situation with respect to physical inactivity due to the pandemic, which is linked to several studies, pointing to sports practice as a beneficial practice to reduce the risk of infection: physical sports practice reduces the risk of acquired infectious disease by $31 \%$ [15].

On the other hand, in this context, there are also lessons learned and opportunities that we must take advantage of to make progress on the SDGs. Some examples are changes in the use of land in public spaces, digitization, the reduction of the use of private vehicles, the increase in green areas and their enhancement, time flexibility or multi-actor and multisector collaboration.

As already stated, the SDGs are universal, which means that they are applied by all countries in the world. Local and regional governments played a key role in defining the SDGs, successfully campaigning for an independent goal on Cities and Urban Settlements (SDG 11) and gaining international recognition of the critical role of local and regional governments in sustainable development.

To implement this global Agenda, it is essential to "locate" these objectives in the different subnational contexts, also taking into account the guidelines set by the European Union and the Government of Spain.

"Localization" refers to taking into account the contexts, challenges, opportunities and subnational governments (regional and local) in all stages of the development of the 2030 Agenda, from the establishment of goals and targets to the determination of the means of implementation and the use of indicators to measure and monitor the progress made.

Among the efforts made to localize the 2030 Agenda in Spain, we can highlight the Spanish Urban Agenda, a national strategic document that seeks to achieve sustainability in 
local urban development policies. It is based on the criteria established by the 2030 Agenda in the new United Nations Urban Agenda and the Urban Agenda for the European Union. As stated in the presentation of said Spanish agenda, it constitutes "a working method and a process for all actors, public and private, who intervene in cities and who seek equitable, fair and sustainable development from their different fields of action" [16-18].

Therefore, the cooperation and sum of efforts of regional and local entities, physical activity and sport as a tool for sustainable development and the promotion of evidencebased practices, represent a combination of elements that should act as a lever policy to drive the cross-cutting progress of the SDGs. To this end, it is critical that governments and other stakeholders embrace this approach to sport as a tool to support the SDGs. Advancing on this path requires defining what we want to measure, standardizing common indicators and methods, and working on the collection and availability of data from these indicators.

It is also important that new studies and practical knowledge are provided in this regard from the academic world. It is no longer a question of determining if it can be a tool to support the 2030 Agenda, but of how it can be maximized, that is, optimizing and expanding the application and impact of its initiatives $[19,20]$.

For all this, as suggested by prominent articles on the matter, it is convenient to search for "policy coherence" as a valuable concept to take into consideration to identify factors that can allow and limit the various potential contributions of sport to the different SDGs. To enhance the contribution of sport to sustainable development, policy makers should assess the possibilities and constraints for implementation at the national level and in subnational (regional and local) contexts. Improving policy coherence in this area requires aligning strategies both within the country and in relations between sport and other sectors, as well as addressing inconsistencies in existing international guidelines in this regard [4,21].

In this article, it is intended to be one more step on this path, highlighting both the possibilities of working with the existing data and the limitations and aspects to be improved. It is intended to illustrate both the need to seek synergies and policy coherence to improve this process and the weaknesses that need to be improved. To do this, it is going to show the existing inequalities between territories in relation to the selected indicators and, at the same time, it seeks to identify some of the main limitations and gaps that we currently find in Spain to make this location more effective. There are different studies and reports that analyze the performance of communities and municipalities in relation to the SDGs in Spain [22,23], but there is a lack of those focused specifically on the Spanish sports framework. As an example of a possible diagnosis and based on the existing data of greater reliability, we will analyze the starting situation in which each of the Spanish Autonomous Communities (Aut. Communities) find themselves in relation to the Kazan Action Plan and its relationship with the following objectives and global Agenda goals 2030:

SDG 3, Health and Wellbeing (target 3.4).

SDG 5, Gender Equality (targets 5.1).

SDG 8, Decent Work and Economic Growth (targets 8.1).

SDG 10, Reduction of Inequalities (target 10.2).

SDG 11, Sustainable Cities and Communities (target 11.7).

\section{Materials and Methods}

Measuring progress on the SDGs is a very important tool for local and regional governments. It makes it easier for them to have a point of reference and offers them relevant information when setting priorities for action. Each of the SDGs has defined targets, and several indicators are established to verify compliance with each target/one.

This diagnosis by Communities aims to provide accessible and understandable data to activate governments, universities, companies, federations and the rest of civil society in solving the great challenges that sport has, as a lever for change, in relation to sustainable development. 
This article aims to take another step on the road when it comes to responding to the challenges around measurements, standardization of indicators and common methods, converging the methodology developed globally by the Sustainable Development Solutions Network (SDSN) for its reports [24] with several of the indications proposed by the Commonwealth Secretariat (with the support of UNESCO) regarding criteria for the selection of goals, targets and indicators in the sports field [6].

This article will analyze the situation of the 17 Spanish Autonomous Communities in relation to a total of 16 quantitative indicators, which are related to the five Sustainable Development Goals mentioned above.

The sports data available from official and reliable sources in Spain are significantly limited. The final selection of indicators in this first analysis and diagnosis focuses in this article on 5 of the 10 SDGs with which sport is most closely related. The selection of indicators (and therefore the results) is strongly conditioned by the availability of data at a subnational scale (in this case, by Autonomous Communities). The data used in this study is available in the sports statistics yearbook of the Spanish Higher Sports Council or in the National Health Survey carried out by the Ministry of Health.

In Table 1, we can see the eight measures proposed in the aforementioned Kazan Action Plan, the SDGs with which they are related and the global Targets of the 2030 Agenda to which sport contributes more directly. Finally, we propose examples of indicators aligned with the recommendations of this international framework on sport and the SDGs.

Table 1. Measures in Kazan Action Plan, relation with Sustainable Development Goals (SDGs), targets and examples of indicators.

\begin{tabular}{|c|c|c|c|}
\hline $\begin{array}{l}\text { Measures to Enhance the Contribution } \\
\text { of Sport to Sustainable Development }\end{array}$ & SDGs & Target & $\begin{array}{l}\text { Examples of Concrete Indicators Aligned with the } \\
\text { Commonwealth Proposal, with the Support } \\
\text { of UNESCO }\end{array}$ \\
\hline $\begin{array}{l}\text { Improve the health and wellbeing of } \\
\text { everyone at any age. }\end{array}$ & SDG 3 & 3.4 & $\begin{array}{l}\% \text { of population sufficiently physically active } \\
\% \text { of the population that practices sports, physical } \\
\text { conditioning and active recreation with some regularity. }\end{array}$ \\
\hline $\begin{array}{l}\text { Make cities and settlements inclusive, } \\
\text { safe, resilient and sustainable. }\end{array}$ & SDG 11 & 11.7 & $\begin{array}{l}\text { Average building surface in cities dedicated to open } \\
\text { spaces for public use for sports, leisure and } \\
\text { active recreation. } \\
\% \text { of the sports budget allocated to the development, } \\
\text { operation and maintenance of sports infrastructures }\end{array}$ \\
\hline $\begin{array}{l}\text { Provide quality education and promote } \\
\text { lifelong learning for all and the } \\
\text { acquisition of skills through sport. }\end{array}$ & SDG 4 & 4.7 & $\begin{array}{l}\% \text { of the total education budget allocated to } \\
\text { Physical Education. }\end{array}$ \\
\hline $\begin{array}{l}\text { Build peaceful, inclusive and } \\
\text { equitable societies. }\end{array}$ & SDG 10 & 10.2 & $\begin{array}{l}\% \text { of sport bodies financed with specific policies that } \\
\text { promote equality and inclusion in sport }\end{array}$ \\
\hline \multirow[t]{2}{*}{$\begin{array}{l}\text { Facilitate economic growth and full and } \\
\text { productive employment and work for all. }\end{array}$} & \multirow{2}{*}{ SDG 8} & 8.1 & $\begin{array}{l}\% \text { of the contribution of sport, physical conditioning and } \\
\text { active recreation to GDP }\end{array}$ \\
\hline & & 8.6 & $\begin{array}{l}\% \text { of employees in sports, fitness and recreation } \\
\text { (leisure) sectors }\end{array}$ \\
\hline \multirow[t]{2}{*}{$\begin{array}{l}\text { Promote equality between men and } \\
\text { women and empower women and girls. }\end{array}$} & \multirow{2}{*}{ SDG 5} & 5.1 & $\begin{array}{l}\% \text { of sports bodies funded that have a strategy or action } \\
\text { plan on gender equality with an allocated budget }\end{array}$ \\
\hline & & 5.5 & $\begin{array}{l}\% \text { of women in positions of president, member of the } \\
\text { council or executive management of sports organizations }\end{array}$ \\
\hline \multirow{2}{*}{$\begin{array}{c}\text { Guarantee sustainable consumption and } \\
\text { production patterns and take urgent } \\
\text { measures to combat climate change and } \\
\text { its effects. }\end{array}$} & SDG 12 & 12.6 & $\begin{array}{l}\text { Annual percentage change in (1) carbon footprint and (2) } \\
\text { recycling rate of (a) large sports facilities and (b) } \\
\text { national events. }\end{array}$ \\
\hline & SDG 13 & 13.1 & $\begin{array}{l}\text { Number of bodies that cite the use of sport or sport } \\
\text { infrastructures in local risk reduction strategies. }\end{array}$ \\
\hline $\begin{array}{l}\text { Build effective and inclusive accountable } \\
\text { institutions at all levels. }\end{array}$ & SDG 16 & 16.6 & $\begin{array}{l}\% \text { of sporting bodies that have adopted policies in favor of } \\
\text { good governance }\end{array}$ \\
\hline
\end{tabular}


The list of indicators used for each SDG, as well as the source of the data and the best and worst value defined for each of them, has been specifically collected in Table 2 . With a view to completing and improving this analysis in future studies, in Table 1 mentioned above, examples of other indicators that are better aligned with said international framework on sport and the SDGs are proposed. These indicators should be carefully taken into account by governments and universities when prioritizing what data to collect in sports matters and where to focus efforts to improve policy coherence in sports management, thus maximizing their contribution to sustainable development.

Table 2. Summary of indicators, source, worst value and best value for each SDG.

\begin{tabular}{|c|c|c|c|c|}
\hline SDGs & Indicator & Source & Worst Value (Min) & Best Value (Max) \\
\hline SDG 3 & $\%$ people doing sport weekly & $\begin{array}{l}\text { Ministry of Culture and Sport. } \\
\text { Survey of Sports Habits in Spain }\end{array}$ & 37.4 & 54.2 \\
\hline SDG 3 & $\%$ sedentary lifestyle leisure time & $\begin{array}{l}\text { Ministry of Health. National } \\
\text { Health Survey in Spain }\end{array}$ & 22.03 & 44.99 \\
\hline SDG 3 & $\%$ federative license & $\begin{array}{l}\text { Higher Sports Council. Federated } \\
\text { Sports Statistics }\end{array}$ & 13.45 & 6.21 \\
\hline SDG 5 & $\begin{array}{l}\% \text { women sport weekly /\% gap } \\
\text { with men }\end{array}$ & $\begin{array}{l}\text { Ministry of Culture and Sport. } \\
\text { Survey of Sports Habits in Spain }\end{array}$ & $32.6 / 13.8$ & $51.1 / 0$ \\
\hline SDG 5 & $\begin{array}{c}\% \text { sedentary lifestyle/\% gap } \\
\text { with men }\end{array}$ & $\begin{array}{l}\text { Ministry of Health. National } \\
\text { Health Survey in Spain }\end{array}$ & $25.96 / 13.48$ & $48.83 / 0$ \\
\hline SDG 5 & $\%$ licenses $/ \%$ gap with men & $\begin{array}{c}\text { Higher Sports Council. Federated } \\
\text { Sports Statistics }\end{array}$ & $2.06 / 71.1$ & $6.96 / 0$ \\
\hline SDG 8 & Sport companies & $\begin{array}{l}\text { Statistics National Institute. } \\
\text { Central Business Directory }\end{array}$ & 6.21 & 12.55 \\
\hline SDG 8 & $\begin{array}{l}€ \text { per person on goods and } \\
\text { services related to sport }\end{array}$ & $\begin{array}{l}\text { Statistics National Institute. } \\
\text { Household Budget Survey. }\end{array}$ & 71 & 189.7 \\
\hline SDG 10 & $\begin{array}{l}€ \text { per person in sport by local } \\
\text { governments }\end{array}$ & $\begin{array}{l}\text { Treasury. Statistical Settlement of } \\
\text { Budgets of Local Entities. }\end{array}$ & 35.65 & 82.02 \\
\hline SDG 10 & $\begin{array}{l}€ \text { per person in sport by } \\
\text { Aut. Communities }\end{array}$ & $\begin{array}{l}\text { Treasury. Statistics on the } \\
\text { Settlement of the Budgets of the } \\
\text { Autonomous Communities. }\end{array}$ & 3.6 & 29.65 \\
\hline SDG 11 & Conventional spaces & $\begin{array}{l}\text { Higher Sports Council. National } \\
\text { Census of Sports Facilities. }\end{array}$ & 23.3 & 65.63 \\
\hline SDG 11 & Singular spaces & $\begin{array}{l}\text { Higher Sports Council. National } \\
\text { Census of Sports Facilities. }\end{array}$ & 0.71 & 11.22 \\
\hline SDG 11 & Areas of activity & $\begin{array}{l}\text { Higher Sports Council. } \\
\text { National Census of } \\
\text { Sports Facilities. }\end{array}$ & 0.24 & 4.56 \\
\hline
\end{tabular}

Drawing on many aspects of the proprietary methodology developed globally by the Sustainable Development Solutions Network (SDSN) for its reports, the data sets prepared have been standardized in percentage or per capita to facilitate comparability. Subsequently, each indicator has been normalized using a scale from 0 to 100, with 100 being the best available score and 0 being the worst. Each value has been normalized from the following formula: $x^{\prime}=\frac{x-\min (x)}{\max (x)-\min (x)}$. On the other hand, for the three indicators related to gender equality, a difference of " 0 " has been considered at a percentage level, with respect to men as the best possible score to be aspired to. In some similar publications of a more informative nature, the data is presented using the traffic light code, green (score higher than 75), yellow (between 51 and 75 points), orange (from 26 to 50) or red (if the score is 25 points or less), thus determining whether or not the objective is reached or if it is on 
the way to being achieved. Additionally, in accordance with the SDSN methodology, no qualitative or quantitative binary indicators have been included in this study [22-25].

To analyze each of the five selected SDGs, a minimum of two indicators have been used. The final score for each SDG is the average scores obtained in each indicator. Regardless of the fact that some SDGs are fed by a greater number of indicators than others, all SDGs have been given equal importance in the final score. The final average mark of each Autonomous Community has been established as a result of the average scores obtained in each of them.

Achieving greater coherence in these policies requires aligning the state sports strategy with that of the implementation of the SDGs, as well as addressing any inconsistencies, limitations and gaps that exist through a process of continuous adjustment and improvement in the relationships that exist between sport and other sectors.

Finally, we consider it necessary to make the following terminological clarifications for each indicator:

$\%$ people doing sports weekly: Spaniards aged 15 and over who say they practice sports at least once a week. Data for 2015.

$\%$ sedentary lifestyle leisure time: Spaniards between 15 and 69 years of age, the population that occupies their free time in an almost totally sedentary way (reading, watching television, going to the cinema, etc.). Data for 2017.

$\%$ federative licenses: Athletes registered (updated annually) in one of the Spanish sports federations, which are the organizational structures whose main function is to officially regulate and organize each of the sports. Data for 2019.

$\%$ women in sports weekly/\% gap with men: Spanish women aged 15 and over who state that they practice sports at least once a week and percentage difference with respect to men. Data for 2015.

\% sedentary lifestyle/\% gap with men: Spanish women between 15 and 69 years old, the population that occupies their free time in an almost totally sedentary way (reading, watching television, going to the movies, etc.) and difference in percentage with respect to the men. Data for 2017.

$\%$ licenses/\% gap with men: Female athletes registered (updated annually) in one of the Spanish sports federations and difference in percentage with respect to men. Data for 2019.

Sport companies: Companies listed in the Central Directory of Companies, whose main economic activity is sports.

$€$ per person on goods and services related to sport: Euros of average expenditure per person on goods and services related to sport. Exploitation of the Household Budget Survey. Data for 2018.

$€$ per person in sports by local governments: Average expenditure paid in sports according to the Statistical Settlement of the Budgets of Local Entities. Data for 2018.

$€$ per person in sports by the Aut. Communities: Average expenditure paid in sports according to the Statistical Settlement of the Budgets of the Aut. Communities. Data for 2018.

Conventional spaces: Sports spaces built for the most common and traditional sports practices, generally having dimensions and enclosures regulated and adapted to the characteristics and type of each sport. Examples include multisport and specialized tracks and fields, athletics tracks and spaces, velodromes, swimming pools, multipurpose and specialized halls, etc. Data for 2005.

Singular Spaces: These are specific spaces and generally have spatial requirements that make their distribution uneven over the territory, such as golf courses, ski resorts, speed circuits, bicycle lanes, shooting ranges, etc. Data for 2005.

Areas of activity: Sports spaces that are distinguished by the lack of definition of their limits and by the environment in which the physical sports practice takes place: land, water or area, for example, mountain bike routes, footpaths and itineraries, climbing areas, railways, shooting and hunting ranges, gliding areas, sailing areas and water sports, etc. Data for 2005. 


\section{Results}

As mentioned, this analysis of the 17 Spanish Autonomous Communities is intended to be an initial look and a possible starting point that provides interested parties with valuable information about their sports situation in relation to these analyzed SDGs.

To analyze SDG 3, Health and Wellbeing, we considered the percentage of people who perform sports weekly (Survey of Sports Habits), the percentage of sedentary lifestyle in leisure time (National Health Survey) and the percentage of people with federative license. As can be seen in Table 3, the Autonomous Community of Navarra stands out very positively in its results for the three indicators, while Castile-La Mancha is in the opposite situation in this comparison.

Table 3. Results and scores related to the indicators established for SDG 3.

\begin{tabular}{|c|c|c|c|c|}
\hline SDG 3 & $\begin{array}{l}\text { \% People Doing } \\
\text { Sport Weekly }\end{array}$ & $\begin{array}{c}\% \text { Sedentary Lifestyle } \\
\text { Lesure Time }\end{array}$ & $\begin{array}{l}\% \text { Federative } \\
\text { License }\end{array}$ & Scores SDG 3 \\
\hline Andalusia & 45.7 & 39.47 & 6.21 & $49,24,0 \rightarrow 24.3$ \\
\hline Aragon & 42.2 & 37.32 & 11.01 & $29,33,66 \rightarrow 42.6$ \\
\hline Asturias & 40.1 & 33.92 & 9.88 & $16,48,51 \rightarrow 38.3$ \\
\hline Balearic Islands & 54.2 & 39.58 & 9.25 & $100,24,42 \rightarrow 55.3$ \\
\hline Basque Country & 46.9 & 30.47 & 12.72 & $57,63,90 \rightarrow 70$ \\
\hline Canary Islands & 46.8 & 41.49 & 8.19 & $56,15,27 \rightarrow 32.6$ \\
\hline Cantabria & 44.2 & 43.83 & 13.45 & $40,5,100 \rightarrow 48.3$ \\
\hline Castile \& Leon & 40.9 & 26.38 & 8.08 & $21,81,26 \rightarrow 42.6$ \\
\hline Cas-La Mancha & 38.6 & 43.18 & 6.6 & $7,8,5 \rightarrow 6.6$ \\
\hline Catalonia & 50.6 & 37.35 & 8.49 & $79,33,31 \rightarrow 47.6$ \\
\hline Extremadura & 41.1 & 29.47 & 10.52 & $22,68,60 \rightarrow 50$ \\
\hline Galicia & 37.4 & 24.27 & 10.46 & $0,90,59 \rightarrow 49.6$ \\
\hline Madrid & 50.5 & 34.48 & 7.86 & $78,46,23 \rightarrow 49$ \\
\hline Murcia & 43.2 & 44.99 & 8.69 & $35,0,34 \rightarrow 23$ \\
\hline Navarre & 53.3 & 22.03 & 12.05 & $95,100,81 \rightarrow 92$ \\
\hline Rioja (La) & 45 & 24.56 & 10.89 & $45,89,65 \rightarrow 66.3$ \\
\hline Valencia & 47 & 37.31 & 7.51 & $57,33,18 \rightarrow 36$ \\
\hline
\end{tabular}

To analyze SDG 5, Gender Equality, we have selected three pairs of indicators closely related to the previous ones of SDG 3. Each pair of indicators analyzes, on the one hand, the percentage of women in the SDG 3 indicators, as well as the difference in said indicator in relation to men. As mentioned above, in these indicators that measure the difference in gender, the value " 0 " has been taken as the best value, far from which all the Autonomous Communities are still (see Table 4). For this reason, none of them has a high final score, although we can see important differences between them. In this sense, Communities, such as Castile-La Mancha, Andalusia and the Region of Murcia, are those that have the most work to do, while Navarre, La Rioja, the Community of Madrid and the Basque Country are those that are in a more favorable starting situation.

On the other hand, as it can be seen in Table 5, in relation to SDG 8, Decent Work and Economic Growth, the Balearic Islands stand out above the rest in terms of the weight of the sports ecosystem in the economy, especially in the number of sports companies for every ten thousand inhabitants. In the case of average spending per person on goods and services related to sport, Navarra and the Basque Country are those that are in the highest range. On the contrary, Castile-La Mancha is the only Autonomous Community that is below 25 points in both indicators. 
Table 4. Results and scores related to the indicators established for SDG 5.

\begin{tabular}{ccccc}
\hline SDG 5 & $\begin{array}{c}\text { \% Women Sport } \\
\text { Weekly/\% Gap with Men }\end{array}$ & $\begin{array}{c}\text { \% Sedentary Lifestyle/\% } \\
\text { Gap with Men }\end{array}$ & $\begin{array}{c}\text { \% Licenses/\% Gap } \\
\text { with Men }\end{array}$ & SDG 5 \\
\hline Andalusia & $41.3 / 9$ & $44.94 / 11.7$ & $2.06 / 66.3$ & $47 / 35,17 / 18,0 / 7 \rightarrow 20.7$ \\
Aragon & $37.1 / 10.4$ & $41.73 / 8.89$ & $4.71 / 56.64$ & $24 / 25,31 / 34,54 / 20 \rightarrow 31.3$ \\
Asturias & $34.3 / 12.3$ & $37.66 / 7.81$ & $4.71 / 50.16$ & $9 / 11,49 / 42,54 / 29 \rightarrow 32.3$ \\
Balearic Islands & $51.1 / 6.3$ & $46.33 / 13.48$ & $4.95 / 46.24$ & $100 / 54,11 / 0,59 / 35 \rightarrow 43.2$ \\
Basque Country & $40.3 / 13.8$ & $32.51 / 4.21$ & $6.57 / 46.94$ & $42 / 0,71 / 69,92 / 34 \rightarrow 51.3$ \\
Canary Islands & $43.2 / 7.4$ & $45.3 / 7.68$ & $4.19 / 48.38$ & $57 / 46,15 / 43,43 / 32 \rightarrow 39.3$ \\
Cantabria & $37.9 / 12.9$ & $48.83 / 10.21$ & $6.77 / 48.1$ & $29 / 7,0 / 24,96 / 32 \rightarrow 31.3$ \\
Castile \& Leon & $38.1 / 5.7$ & $30.26 / 7.82$ & $3.48 / 56.26$ & $30 / 59,81 / 42,29 / 21 \rightarrow 43.7$ \\
Cas-La Mancha & $32.6 / 12$ & $47.39 / 8.37$ & $2.54 / 61.48$ & $0 / 13,6 / 38,10 / 14 \rightarrow 13.5$ \\
Catalonia & $47.9 / 5.5$ & $41.96 / 9.41$ & $4.26 / 49$ & $83 / 60,30 / 30,45 / 31 \rightarrow 46.5$ \\
Extremadura & $38.9 / 4.4$ & $31.51 / 4.1$ & $3.01 / 71.1$ & $34 / 68,76 / 70,19 / 0 \rightarrow 44.5$ \\
Galicia & $32.8 / 9.7$ & $26.49 / 4.6$ & $4.68 / 53.58$ & $1 / 30,98 / 66,53 / 25 \rightarrow 45.5$ \\
Madrid & $47.8 / 5.7$ & $47.23 / 43.84$ & $82 / 59,48 / 48,44 / 38 \rightarrow 53.2$ \\
Murcia & $36.4 / 13.5$ & $46.73 / 3.49$ & $3.25 / 62.6$ & $21 / 2,9 / 74,24 / 12 \rightarrow 23.7$ \\
Navarra & $47.8 / 12.2$ & $26 / 8.06$ & $6.96 / 41.58$ & $82 / 12,100 / 40,100 / 42 \rightarrow 62.7$ \\
Rioja (La) & $41.6 / 6.8$ & $25.96 / 2.84$ & $5.21 / 51.5$ & $49 / 51,100 / 79,64 / 28 \rightarrow 61.8$ \\
Valencia & $42.6 / 9.1$ & $40.85 / 7.17$ & $2.83 / 61.68$ & $54 / 34,34 / 47,16 / 13 \rightarrow 33$ \\
\hline
\end{tabular}

Table 5. Results and scores related to the indicators established for SDG 8.

\begin{tabular}{cccc}
\hline SDG 8 & Sport Companies & $\begin{array}{c}\text { € Per Person on Goods and } \\
\text { Services Related to Sport }\end{array}$ & Scores SDG 8 \\
\hline Andalusia & 6.42 & 108.8 & $3,32 \rightarrow 17.5$ \\
Aragon & 7.54 & 152.9 & $21,69 \rightarrow 45$ \\
Asturias & 7.99 & 118.3 & $28,40 \rightarrow 34$ \\
Balearic Islands & 12.55 & 134.5 & $100,53 \rightarrow 76.5$ \\
Basque Country & 6.21 & 170 & $0,83 \rightarrow 41.5$ \\
Canary Islands & 10.18 & 77.7 & $63,6 \rightarrow 34.5$ \\
Cantabria & 8.77 & 115.6 & $40,38 \rightarrow 39$ \\
Castile \& Leon & 8.83 & 101.2 & $41,25 \rightarrow 33$ \\
Cas-La Mancha & 6.91 & 71 & $11,0 \rightarrow 5.5$ \\
Catalonia & 8.11 & 145.4 & $30,63 \rightarrow 46.5$ \\
Extremadura & 6.51 & 102.8 & $5,27 \rightarrow 16$ \\
Galicia & 8.48 & 83.4 & $36,10 \rightarrow 23$ \\
Madrid & 8.17 & 116.3 & $31,38 \rightarrow 34.5$ \\
Murcia & 7.04 & 138.7 & $13,57 \rightarrow 35$ \\
Navarre & 8.24 & 189.7 & $32.100 \rightarrow 66$ \\
Rioja (La) & 7.95 & 144.9 & $27,62 \rightarrow 44.5$ \\
Valencia & 7.82 & 122.3 & $25,43 \rightarrow 34$ \\
\hline
\end{tabular}

Regarding the indicators established to value sport in relation to the Reduction of Inequalities (SDG 10), the per capita public expenditure paid by both the Autonomous Communities and the total of their local governments has been analyzed previously during the year corresponding to 2018.

As shown in Table 6, in this sense, by Autonomous Communities, we observe abysmal differences between them. Navarre stands out significantly, in terms of its expenditure on sports per person, paying an expenditure more than 8 times higher than Castile-La Mancha. As far as local governments are concerned, those that invest the most are those of the Basque Country, exceeding 82 euros per inhabitant. 
Table 6. Results and scores related to the indicators established for SDG 10.

\begin{tabular}{cccc}
\hline SDG 10 & $\begin{array}{c}\text { € Per Person in Sport by } \\
\text { Local Governments }\end{array}$ & $\begin{array}{c}\text { € Per Person in Sport by } \\
\text { Aut. Communities }\end{array}$ & Scores SDG 10 \\
\hline Andalusia & 40.75 & 4.37 & $11,3 \rightarrow 7$ \\
Aragon & 67.77 & 7.75 & $69,16 \rightarrow 42.5$ \\
Asturias & 45.56 & 11.27 & $21,29 \rightarrow 25$ \\
Balearic Islands & 63.58 & 21.72 & $60,70 \rightarrow 65$ \\
Basque Country & 82.02 & 6.21 & $100,10 \rightarrow 55$ \\
Canary Islands & 59.1 & 5.63 & $51,8 \rightarrow 29.5$ \\
Cantabria & 55.93 & 12.99 & $44,36 \rightarrow 40$ \\
Castile \& Leon & 52.95 & 6 & $37,9 \rightarrow 23$ \\
Cas-La Mancha & 53.78 & 3.6 & $39,0 \rightarrow 19.5$ \\
Catalonia & 50.96 & 8.38 & $33,18 \rightarrow 25.5$ \\
Extremadura & 47.85 & 15.37 & $26,45 \rightarrow 35.5$ \\
Galicia & 45.15 & 8.26 & $20,18 \rightarrow 19$ \\
Madrid & 49.71 & 4.45 & $30,3 \rightarrow 16.5$ \\
Murcia & 35.65 & 4.44 & $0,3 \rightarrow 1.5$ \\
Navarre & 67.81 & 29.65 & $69,100 \rightarrow 84.5$ \\
Rioja (La) & 57.98 & 20.24 & $48,64 \rightarrow 56$ \\
Valencia & 39.87 & 7.2 & $9,14 \rightarrow 11.5$ \\
\hline
\end{tabular}

Among those who spend the least on sport, we find the Region of Murcia, Andalusia, the Valencian Community and Galicia; both their regional governments and their local entities have the lowest results in this matter.

In the case of the contribution of sport to SDG 11, we considered the number of sports spaces, both conventional and singular, and activity areas available to the citizens of the different Autonomous Communities for every ten thousand inhabitants.

As can be seen in Table 7, no Autonomous Community stands out clearly above the rest in more than one of these indicators. However, the Balearic Islands are, once again, the one that obtains the most outstanding results and the one that leads in the number of conventional sports venues. On the other hand, in the number of singular spaces, Cantabria is the one that dominates above the rest. Regarding the number of areas of activity, the best result is presented by Asturias in a fairly accentuated way.

Table 7. Results and scores related to the indicators established for SDG 11.

\begin{tabular}{ccccc}
\hline SDG 11 & $\begin{array}{c}\text { Conventional } \\
\text { Spaces }\end{array}$ & Singular Spaces & $\begin{array}{c}\text { Areas of } \\
\text { Activity }\end{array}$ & Scores SDG 11 \\
\hline Andalusia & 29.49 & 1 & 0.87 & $15,3,15 \rightarrow 11$ \\
Aragon & 52.48 & 3.73 & 1.65 & $69,29,33 \rightarrow 43.7$ \\
Asturias & 29.22 & 4.64 & 4.56 & $14,37,100 \rightarrow 50.3$ \\
Balearic Islands & 65.63 & 6.38 & 2.58 & $100,54,54 \rightarrow 69.3$ \\
Basque Country & 32.34 & 3.69 & 0.58 & $21,28,8 \rightarrow 19$ \\
Canary Islands & 40.4 & 4.06 & 1.21 & $40,32,22 \rightarrow 31.3$ \\
Cantabria & 32.77 & 11.22 & 0.69 & $22,100,11 \rightarrow 44.3$ \\
Castile \& Leon & 53.52 & 4.29 & 0.96 & $71,34,17 \rightarrow 40.7$ \\
Cas-La Mancha & 38 & 1.7 & 2.29 & $35,9,47 \rightarrow 30.3$ \\
Catalonia & 36.9 & 2.16 & 2.06 & $32,14,42 \rightarrow 29.3$ \\
Extremadura & 40.64 & 1.93 & 2.25 & $41,12,47 \rightarrow 33.3$ \\
Galicia & 33.86 & 1.75 & 0.85 & $25,10,14 \rightarrow 16.3$ \\
Madrid & 23.3 & 0.99 & 0.24 & $0,3,0 \rightarrow 1$ \\
Murcia & 23.62 & 1.23 & 0.24 & $1,5,0 \rightarrow 2$ \\
Navarre & 45.5 & 2.9 & 0.86 & $52,21,14 \rightarrow 29$ \\
Rioja (La) & 48.2 & 2.62 & 1.07 & $59,18,19 \rightarrow 32$ \\
Valencia & 28.92 & 0.71 & 0.26 & $13,0,0 \rightarrow 4.3$ \\
\hline
\end{tabular}

On the contrary, in this comparison, the Community of Madrid, the Region of Murcia, the Valencian Community, Andalusia and Galicia are the only communities whose results 
are located in the lowest range ( 25 points or less) in conventional, singular and areas of activity.

As it can be seen in Table 8, no Autonomous Community has a performance level higher than 75 points, which would correspond to the highest rank in relation to the SDGs analyzed. In fact, the only community whose results exceed this threshold of 75 points in more than one SDG is Navarre, which, as it can be seen, does so in SDG 3 and 10. Aside from these, the other exception, with a final value of the highest rank, is for the Balearic Islands, which is obtained in SDG 8, Decent Work and Economic Growth. In addition, these two communities (Navarre, followed by the Balearic Islands) are the ones that obtained the best final average score in this relationship between sport and the SDGs. However, following the SDSN criteria, their final scores correspond to the yellow color, which means that they are in the medium-high range, with none of them reaching the highest range in this final mean (green color). The third community with the best score is La Rioja, also standing at this medium-high level.

Table 8. Summary of the scores in each SDG analyzed and the final average for each Autonomous Community.

\begin{tabular}{ccccccc}
\hline Final Summary & SDG 3 & SDG 5 & SDG 8 & SDG 10 & SDG 11 & Final Score SDGs \\
\hline Andalusia & 24.3 & 20.7 & 17.5 & 7 & 11 & 16.1 \\
Aragon & 42.6 & 31.3 & 45 & 42.5 & 43.7 & 41 \\
Asturias & 38.3 & 32.3 & 34 & 25 & 50.3 & 36 \\
Balearic Islands & 55.3 & 43.2 & 76.5 & 65 & 69.3 & 61.9 \\
Basque Country & 70 & 51.3 & 41.5 & 55 & 19 & 47.4 \\
Canary Islands & 32.6 & 39.3 & 34.5 & 29.5 & 31.3 & 38.1 \\
Cantabria & 48.3 & 31.3 & 39 & 40 & 44.3 & 40.6 \\
Castile and Leon & 42.6 & 43.7 & 33 & 23 & 40.7 & 36.6 \\
Castile-La & 6.6 & 13.5 & 5.5 & 19.5 & 30.3 & 15.1 \\
Mancha & 47.6 & 46.5 & 46.5 & 25.5 & 29.3 & 39.1 \\
Catalonia & 50 & 44.5 & 16 & 35.5 & 33.3 & 35.9 \\
Extremadura & 49.6 & 45.5 & 23 & 19 & 16.3 & 30.7 \\
Galicia & 49 & 53.2 & 34.5 & 16.5 & 1 & 30.8 \\
Madrid & 23 & 23.7 & 35 & 1.5 & 2 & 17 \\
Murcia & 92 & 62.7 & 66 & 84.5 & 29 & 66.8 \\
Navarre & 66.3 & 61.8 & 44.5 & 56 & 32 & 52.1 \\
Rioja (La) & 36 & 33 & 34 & 11.5 & 4.3 & 23.8 \\
Valencia & & & & & & \\
\hline
\end{tabular}

In the average values of each ODS (Change for SDG), those that would occupy the orange color band, corresponding to the medium-low range, predominate, so much so that the vast majority of communities (10 in total) present a final average value in this range, which are, from highest to lowest score, the Basque Country, Aragon, Cantabria, Catalonia, the Canary Islands, Castile and Leon, Asturias, Extremadura, Community of Madrid and Galicia.

Finally, the four remaining Communities occupy the lowest rank, identified in red and corresponding to a final average score of less than 25 points. Among them, the Valencian Community has a slightly more favorable situation, since it obtains a figure very close to the orange range, a level of performance found in three of these five SDGs.

The rest of the communities with the lowest starting point in this analysis are the Region of Murcia, Andalusia, which is the only one that does not exceed 25 points in any of the five SDGs analyzed, and Castile-La Mancha, which, although it reaches the orange level in relation to SDG 11, it does not escape of being the Autonomous Community with a lower final score.

\section{Discussion}

This article tries to generate knowledge and contribute to the coherence of policies through the use of indicators in the international framework of the SDGs and the 2030 
Agenda. These indicators provide us with a vision of the situation of sport in relation to the SDGs in the different Communities of the Spanish territory and to highlight some important limitations or aspects to improve. Aligning sports strategies with the rest of international priorities makes it easier for those responsible for sports policies to set priorities for action, establish synergies and be in a better position to offer sport as a tool to face the global challenges to which we confront as a society.

In this analysis, an assessment is made based on a series of indicators from the sports field related to five prioritized SDGs. In it, as in the REDS (SDSN in Spain) and SDSN reports, the situation of all organizations, both public and private, is evaluated and not only the action of a specific agent. As we said before, the results collected in this study do not attribute success or failure to a specific administration but rather describe a reality in which all levels of government have shared responsibility and, depending on the specific area, point to a greater or lesser prominence of each one of them.

In relation to SDG 3 , at the state level, only $46.2 \%$ of the population has a habit of physical sporting practice, while those who do so with a federative license are only $8.39 \%$. On the other hand, the percentage of sedentary people in leisure time stands at $37.31 \%$. Analyzing the results obtained, we appreciate a significant difference between Autonomous Communities, with the Communities of the northern half of Spain generally obtaining a higher score than those of the southern half. These levels, as is the case in many countries, are still far from the recommendations of the World Health Organization [26] for the prevention of noncommunicable diseases, which is why they promote global action plans on physical activity that have to be taken into account [27].

The indicators related to SDG 3, Health and Wellbeing, are also taken as a reference to analyze SDG 5, Gender Equality. Although the trend remains regarding the northsouth difference, the results show significant inequality in this matter, with results being more positive in men than in women in all indicators and all territories. For this reason, no Autonomous Community reaches the highest rank in the final mean assessment, the final scores being generally medium or low. These results confirm that sport is still a traditionally masculine field in which the gender inequalities existing in other areas of society are manifested even more clearly. There is still a lot of work to be done between now and 2030 for gender equality and the great importance of national sports programs, such as "Woman Universe" of the Higher Sports Council, whose objective is the promotion and increase of female participation in all areas of sport; they are also aligned with the international premises of the 2030 Agenda to improve their effectiveness.

With regard to SDG 8, Decent Work and Economic Growth, the Balearic Islands and the Canary Islands show the highest rate of companies related to sports, which reaffirms, among other aspects, the positive interaction between leisure, sports and tourism [28]. Regarding the average expenditure per person on sports goods and services, it is evident that it is largely conditioned by the differences in purchasing power of the different territories, but there are also considerable differences that do not correspond to this parameter and whose causes could be studied in greater depth. In relation to this SDG, it should be remembered that, according to the Commonwealth proposal, it would be more convenient to measure the percentage of employees in the sports, fitness and leisure sectors.

To analyze SDG 10, the Reduction of Inequalities, the indicators that have been taken as a reference have to do with the public spending settled in the sports field both by the Autonomous Communities and by their local governments, appreciating very important investment differences between the different Spanish territories. This information is valuable but very limited. It is necessary to develop a common budget alignment framework that serves as a comparative element to analyze good practices and identify the economic efforts made towards sustainability. This would allow the use of very specific indicators in the direction of the goals of each of the SDGs established by the 2030 Agenda, such as, in relation to goal 10.2 of the SDGs, the number of sports bodies financed with policy's specific measures that promote equality and inclusion in sport and the investment made for it. 
Finally, we have included a study of SDG 11, Sustainable Cities and Communities, based on data from conventional and singular sports spaces and areas of activity according to the National Census of Sports Facilities, whose official information dates from 2005. It is a clear example of the need to update data sources like this one and, since the sports ecosystem has not stopped growing, probably a first step to improve in all communities is simply to update them and, incidentally, do so having taken into account aspects marked by national and international agendas, such as the Spanish Urban Agenda. In this sense, it would be very interesting to obtain information, for example, on the average proportion of built-up areas in cities dedicated to open spaces for public use for sports, leisure and active recreation (target 11.7 of the SDGs).

In general, as the results obtained show, sports-related data of most of the Spanish Autonomous Communities are at levels far from being satisfactory with respect to the SDGs. The predominant range in these results is orange, followed by red, yellow, and finally green. Therefore, the starting position in most of the indicators is medium or low in relation to the best results of other Autonomous Communities or, as is the case in the indicators that assess the difference in terms of gender, to the goals set globally by 2030 (that is, no such difference). Although a comparison is made between Communities, what is intended with this analysis is not to elaborate a ranking with winners and losers but to provide the interested parties with relevant information that is a motivation to improve the values in which they present a worse performance, look for the factors that are proving differential and develop strategies aligned with the SDGs that allow us to improve them and do so in the most efficient way.

It must be taken into account that this analysis has only included as an example 16 indicators associated with 5 of the 10 SDGs which sport is related with in the Kazan Action Plan. The data and tables provided can serve as support and reference elements to work for sustainability through sport. For this reason, and in accordance with the provisions of the mentioned Action Plan, it is necessary to develop more appropriate indicators and better adapted to international agendas indicators, to achieve a common measurement system of the SDGs in the field of sport.

As has been observed, there are important inequalities between territories in relation to the selected indicators, which can be identified as another of the limitations and gaps that must be addressed with a national strategy that guides the policies that are carried out in this regard to all levels. In addition, as occurs in other studies similar to this one related to the degree of compliance with the SDGs, in many cases, what can be measured is measured but not always with what would be the most appropriate indicator. One of the main problems is that the databases are not standardized and there are serious shortcomings in them that must be taken into account in the National Statistical Plan developed by the Ministry together with the Higher Sports Council. In addition to the aspects to take into account that have been discussed in this section in relation to each of the SDGs, numerous variables have also been identified, such as those included in Table 1, which would need to be measured at all levels (from national to local) in the sports field. This is a fundamental aspect for improving the quantity and quality of available data and their usefulness for the SDGs.

Likewise, it will be necessary to establish, whenever possible, the desirable thresholds to be achieved between now and 2030 in relation to each of the selected indicators, so that the level of performance does not depend on a comparison with that of other actors.

In the analysis of each of the SDGs, some considerations have been included on how policy coherence can be improved, based on international recommendations in each of the areas and on the prioritized goals in relation to each of the SDGs.

As mentioned, improving the contribution of sport to the achievement of the SDGs largely involves improving these issues that provide greater coherence to sports policies and facilitate their alignment with the different strategies for the implementation of the SDGs. In addition, it is necessary to address the inconsistencies, limitations and gaps that 
have been identified through a process of adjustment and continuous improvement in the existing relationships between sports and other sectors.

Once these initial diagnostic studies have been improved, the design of intervention strategies and a process of monitoring and evaluating the evolution of each indicator should follow to verify the effectiveness of the efforts made in this shared responsibility towards a more sustainable world.

\section{Conclusions}

Currently, worldwide and in Spain, there is growing concern and involvement in working effectively and in a coordinated manner in the implementation of the 2030 Agenda.

Sport must play a very important role in this process of implementation of the SDGs at all levels. The network of associative facilities and structures of the sports ecosystem can act as a lever for change capable of multiplying the results of the actions carried out. This planning process should not be done as an isolated process but rather by coupling and integrating into broader strategic documents, such as the Spanish Urban Agenda and other action plans.

The results, as mentioned, show a significant disparity between territories. These important differences and the existing level of decentralization in Spain make a common sports strategy essential to cement the vertical coherence of sports policies, facilitating the alignment and connection of global sports strategies with local ones, counting for their definition with the different levels of government. On the other hand, this decentralization will allow each Autonomous Community, in collaboration with the rest of the state levels, to adapt its strategy and resources to those aspects in which they are most necessary, based on the results obtained in the diagnosis.

The different administrations must identify where the promotion of sport can be a more differential factor in the achievement of the objectives of the SDGs and, at the same time, where the achievement of some objectives can further enhance sport and its positive aspects. For this, it is absolutely necessary to seek coherence in sports policies to improve their contribution to sustainable development. Unifying criteria in this sense will facilitate, at the same time, increase in the quality and quantity of data and a common measurement framework will allow governments, sports organizations and the private sector information on where and how to intervene. In this process, in order to multiply the results and for sport to act as a lever police force, it will also be essential to improve the horizontal coherence of these policies, taking special relevance for this the formation of alliances, the exchange of experiences and the definition of roles between the different actors (state and nonstate) [29].

Therefore, the main challenge we must face is to resolve with determination the existing deficiencies, take advantage of the strengths and opportunities that sport presents us and define concrete and viable projects framed in the sustainability strategies that are defined in the short, medium- and long-term.

Governments and other agents, both public and private, that are capable of placing sport in this line of regeneration and sustainability, promoted if carried out, more vigorously as a result of the current Covid-19 crisis, will be prepared to opt for new and greater sources of funding, both national and European.

A clear example of this is the recovery plan agreed on 21 July 2020, by EU leaders, on the 2021-2027 multiannual financial framework, marking the way toward the end of the crisis caused by the pandemic and establishing the foundations for a modern and more sustainable Europe.

In addition, as a result of this, in October 2020, the Government of Spain presented the Transformation, Recovery and Resilience Plan, in which the promotion of culture and sports has been included as one of the 10 lever policies for a sustainable and inclusive growth.

Consequently, many of the resources to be promoted will be framed in the context of the SDGs in this quest to contribute to cities and a more sustainable society. A state strategy is needed more than ever to serve as a roadmap to guide policies based on lessons learned 
and international recommendations, contribute to solving existing gaps and guarantee a coordinated and coherent use of these resources that allows maximizing the contribution from sport to sustainable development. It is up to all the actors in the sports field to actively join in this process and contribute to defining those transformative projects for the future $[20,21,29]$.

Author Contributions: Conceptualization, J.C.-S.; Formal analysis, J.C.-S.; Investigation, E.S.-V.; Methodology, E.S.-V.; Project administration, A.D.-S.; Resources, A.D.-S.; Supervision, V.M.-B.; Validation, E.S.-V.; Visualization, A.D.-S.; Writing-original draft, J.C.-S.; Writing-review \& editing, V.M.-B. All authors have read and agreed to the published version of the manuscript.

Funding: This research received no external funding.

Institutional Review Board Statement: Not applicable.

Informed Consent Statement: Not applicable.

Data Availability Statement: Not applicable.

Conflicts of Interest: The authors declare no conflict of interest.

\section{References}

1. United Nations. Transforming our world: The 2030 Agenda for Sustainable Development. Resolution A/RES/70/1 adopted. In Proceedings of the United Nations General Assembly at its Seventieth Session, New York, NY, USA,15 September23 December 2015.

2. Varela, F.; Álvaréz, B.; Cortés, J. Guide for Locating the 2030 Agenda; Ministry of Social Rights and 2030 Agenda: Madrid, Spain, 2020.

3. Cáceres, F. Sport as a Tool for Sustainable Developmen; Ibero-American Sports Council: Montevideo, Uruguay, 2019.

4. Lindsey, I.; Darby, P. Sport and the sustainable development goals: Where is the policy coherence? Int. Rev. Sociol. Sport 2019, 54, 793-812. [CrossRef]

5. UNESCO. Kazan Action Plan. In Proceedings of the Sixth International Conference of Ministers and Senior Officials in Charge of Physical Education and Sports (MINEPS VI), Kazan, Russia, 13-15 July 2017.

6. Commonwealth Secretariat. Measure the Contribution of Sport, Physical Education and Physical Activity to the Sustainable Development Goals; The Commonwealth: London, UK, 2019.

7. Government of Spain. Action Plan for the Implementation of the 2030 Agenda. Towards a Spanish Strategy for Sustainable Development; Ministry of Foreign Affairs, European Union and Cooperation: Madrid, Spain, 2018.

8. UNESCO. International Charter of Physical Education, Physical Activity and Sport. In Proceedings of the 38th session of the General Conference of UNESCO, Paris, France, 3-18 November 2015.

9. COLEF Council. Manifesto for the consideration of the provision of Physical Education, Physical Activity and Sport services as an essential activity also during the Covid-19 pandemic. In Proceedings of the General Council of Physical and Sports Education, Madrid, Spain, 16 November 2020.

10. European Comission. White Book of Sport; COM 391: Brussels, Belgium, 11 July 2007.

11. Booth, F.W.; Roberts, C.K.; Laye, M.W. Lack of exercise is a major cause of chronic diseases. Compr. Physiol. 2012, 2, 1143-1211. [PubMed]

12. Pedersen, B.K.; Saltin, B. Exercise as medicine-evidence for prescribing exercise as therapy in 26 different chronic diseases. Scand. J. Med. Sci. Sports 2015, 25, 1-72. [CrossRef] [PubMed]

13. Strain, T.; Brage, S.; Sharp, S.J.; Richards, J.; Tainio, M.; Ding, D.; Benichou, J.; Kelly, P. Use of the prevented fraction for the population to determine deaths averted by existing prevalence of physical activity: A descriptive study. Lancet Glob. Health 2020, 8, e920-e930. [CrossRef]

14. Mayo, X.; Del Villar, F.; Jiménez, A. Sedentary Thermometer in Spain: Report on Physical Inactivity and Sedentary Lifestyle in the Spanish Adult Population; Active Spain Foundation: Madrid, Spain, 2017.

15. Chastin, S.; Abaraogu, U.; Bourgois, J.; Dall, P.; Darnborough, J.; Duncan, E.; Dumortier, J.; Pavón, D.J.; McParland, J.; Roberts, N. Physical Activity, Immune Function and Risk of Community Acquired Infectious Disease in the General Population: Systematic Review and Meta-Analysis. SSRN. 2020. Available online: https:/ / ssrn.com/abstract=3673184 (accessed on 8 January 2021).

16. Ministry of Development. Spanish Urban Agenda 2019; Ministry of Development: Madrid, Spain, 2018.

17. United Nations. New Urban Agenda (Habitat III). In Proceedings of the United Nations Conference on Housing and Sustainable Urban Development, Approved by the United Nations General Assembly in Resolution 71/256, Quito, Ecuador, 23 December 2016.

18. European Commission Urban Agenda for the UE; European Commission: Amsterdam, The Netherlands, 2016.

19. CID. Sport as a Tool for Sustainable Development. Conceptual Introduction and Review of Experiences. PART 1; Ibero-American Sports Council: Montevideo, Uruguay, 2019. 
20. CID. Sport as a Tool for Sustainable Development. Prospects, Advances and Opportunities, PART 2; Ibero-American Sports Council: Montevideo, Uruguay, September 2019.

21. Lindsey, I.; Chapman, T. Enhancing the Contribution of Sport to the Sustainable Development Goals; Commonwealth Secretariat: London, UK, 2017.

22. de Madriaga, I.S.; López, J.G.; Sisto, R. The Sustainable Development Goals in 100 Spanish Cities; Spanish Network for Sustainable Development (REDS): Madrid, Spain, 2018.

23. REDS. The SDGs in 100 Spanish Cities, 2nd ed.; REDS: Madrid, Spain, 2020.

24. SDSN. SDG Index and Dashboards Report 2017. In Global Responsabilities International Spillovers in Achieving the Goals; Bertelsmann Stiftung and Sustainable Development Solutions Network: New York, NY, USA, 2017.

25. Prakash, M.; Teksoz, K.; Espey, J.; Sachs, J.; Shank, M.; Schmidt-Traub, G. The US Cities Sustainable Development Goals Index 2017. Achieving a Sustainable Urban America; SDSN: New York, NY, USA, 2017.

26. WHO. Montevideo Roadmap 2018-2030 on Non-Communicable Diseases; World Health Organization: Geneva, Switzerland, 2017.

27. OPS. More Active People for a Healthier World. Global Action Plan on Physical Activity 2018-2030; Pan American Health Organization: Washington, DC, USA, 2019.

28. Reverter-Masia, J.; Plaza-Montero, D. Leisure, Sports and Tourism. Current Situation and Business Lines. Esporte Soc. 2010, 6. Available online: https:/ / www.cabdirect.org/cabdirect/abstract/20113386474 (accessed on 15 January 2021).

29. Lindsey, I.; Chapman, T.; Dudfield, O. Configuring relationships between state and non-state actors: A new conceptual approach for sport and development. Int. J. Sport Policy Politics 2019, 12, 127-146. [CrossRef] 